\title{
A desteologização da bioética e o nascimento da ética como nova instituição específica ${ }^{1}$
}

\author{
Maurizio Mori \\ Tradução de Erick Araujo ${ }^{3}$ e Fermin Roland Schramm ${ }^{4}$
}

\begin{abstract}
Resumo:Adesteologizaçãodabioéticaéuma dasmaiores transformações doimaginário social já ocorridas, análoga à ocorrida com o Romantismo. A interdisciplinaridade é seu maior efeito em nível institucional. A demanda por justificativas racionais é seu efeito em nível metodológico. Em um nível mais profundo, seu efeito é sobre seu próprio objeto de reflexão: a vida humana, que passa a ser percebida de uma maneira radicalmente nova.
\end{abstract}

Palavras-chave: bioética; interdisciplinaridade; ética tradicional; revolução biomédica.

\section{La Deteologización de la bioética y el nacimiento de la ética como nueva institución específica}

Resumen: La deteologización es una de las mayores transformaciones del imaginario social ya ocurridas, análoga a la ocurrida con el Romanticismo. La interdisciplinaridad es su mayor efecto a nivel institucional. La demanda por justificaciones racionales es su efecto a nivel metodológico. En un nivel más profundo, su efecto es sobre su propio objeto de reflexión: la vida humana, que pasa a ser percibida de una manera radicalmente nueva.

Palabras clave: bioética; interdisciplinariedad; ética tradicional; revolución biomédica.

${ }^{1}$ Publicado originalmente em Quaderni di Diritto e Politica Ecclesiastica, n.01, aprile 2015. Tradução autorizada pelo autor e pela revista, recebido em 08/01/18 e aprovado em 01/07/18.

${ }^{2}$ Professor do departamento de Filosofia e Ciência da Educação da Universidade de Turim, Itália, e-mail: maurizio.mori@unito.it

${ }^{3}$ Bolsa CAPES/PDSE, Santarém, Pará, Brasil, e-mail: ericklaraujo@gmail.com

${ }^{4}$ Escola Nacional de Saúde Pública (ENSP), Rio de Janeiro, Rio de Janeiro, Brasil, e-mail: roland@ensp.fiocruz.br 


\title{
The de-theologization of bioethics and the birth of ethics as a new specific institution
}

\begin{abstract}
Detheologization of bioethics is one of the greatest transformations of social consciousness to have ocurred, analogous to that which ocurred with Romanticism. Its major effect at the institutional level is interdisciplinary. At the methodological level detheologization supported rational justification, while at the deepest level it was about bioethics' object of reflection: human life, which is now perceived in a radically new way.
\end{abstract}

Keywords: bioethics; interdisciplinary; traditional ethics; biomedical revolution.

\section{Introdução}

\section{Explanação terminológica preliminar}

O termo "desteologização" (de-teologizzazione) não aparece nem no Lessico universale italiano (1970) nem no Vocabolario della lingua italiana (1987); não se encontra, tampouco, nos vários dicionários disponíveis, hoje, em rede. Parece não haver uma definição codificada na linguagem comum. Pode-se dizer que se trata de um termo técnico ligado, majoritariamente, a dois contextos: os estudos de (e sobre) Carl Schmitt, nos quais se procura mostrar o processo de formação do poder político estatal típico da modernidade ${ }^{5}$; os estudos de direito canônico, onde ressalta-se o esforço em evitar a tentação formalística que priva a norma da versatilidade necessária ao contexto histórico e ao sopro do Espírito $^{6}$. O termo reaparece em outros contextos (na geografia,

\footnotetext{
${ }^{5}$ Para C. Schmitt, a desteologização está ligada à racionalização da vida social e pertence ao grande movimento histórico que, do século XVI ao XIX, levou ao poder estatal.

${ }^{6}$ No direito canônico, o termo foi usado por URRESTI (1967) para indicar a tarefa do canônico empenhado em evitar o erro de imobilizar a norma com o rigor absoluto da verdade teológica: "uma vez que parece que esse pecado foi cometido mais de uma vez, não é estranho que, nesse sentido, se fala de 'desteologização' do direito canônico, não para privá-lo de seu núcleo
} 
por exemplo). Por vezes, se fala de "desteologização da religião" para relevar o ato com o qual ela é reconhecida "como fato antropologicamente necessário" que por meio de ritos, símbolos e instituições opera funções sociais estabilizantes, ao ponto de ser vista "como 'estrutura que sustenta o estado' a partir da perda de uma singular e autêntica religiosidade através da teoria política e do poder" (LEINKAULF, 2011, p.08).

É difícil estabelecer um mínimo denominador comum considerada a variedade de acepções; por isso usamos o termo desteologização em lugar de secularização, entendida não em seu significado (jurídico) de redução do clérigo ao estado laico ou de passagem de uma instituição religiosa ao Estado, mas naquele (sociológico) que indica o processo cultural que leva ao desencanto do mundo e à consequente perda do senso de fascínio e de temor, origem da dependência e da subordinação ao divino. Percebe-se que o termo secularização permanece controverso ${ }^{7}$; por isso pode ser oportuno substituí-lo pelo termo desteologização que, em princípio,

teológico, mas para extrair, sem adição, seu autêntico conteúdo teológico".

${ }^{7}$ A controvérsia depende do fato de que, para alguns, "secularização" indica o processo que no Ocidente, pela influência do cristianismo, levou à autonomia do mundano em relação ao divino, consentindo a formação de linguagens e saberes (científicos) distintos da religião, e o controle de âmbitos da vida prescindindo de um referimento direto ao religioso. Entendida assim, a secularização liberaria a religião de eventuais elementos mágicos e evitaria que se tornasse uma ideologia política específica, sem, contudo, invalidála de algum modo. De fato, a distinção do secular em relação ao divino é compatível com a fé e, mesmo, favoreceria uma fé no Transcendente mais autêntica pois purificada dos resíduos da religiosidade natural. Nesse sentido, a secularização seria boa porque aberta à fé.

Para outros, de forma inversa, a secularização implicaria apenas a proclamação da total independência do secular em relação ao religioso, ao ponto de se considerar a religião como algo supérfluo ou danoso. O horizonte secular se torna o único capaz de uma existência real, porque o horizonte religioso seria fruto de ilusões ou de sentimentos distorcidos a serem superados. Esta posição, por vezes, vem indicada com o termo "secularismo" para sublinhar que o secular é exaustivo e exclui a religião. 
apresenta-se como mais asséptico e neutro. Talvez não seja o suficiente para evitar eventuais mal-entendidos, mas podemos, ao menos, prosseguir com nossa análise e adiar uma reflexão mais aprofundada sobre o tema.

\section{Desenvolvimento}

\section{A desteologização da bioética no plano institucional}

A bioética nasce entre os anos 1960 e os primeiros anos 1970, quando pessoas estudiosas de diversas disciplinas começaram a refletir de modo sistemático e coordenado sobre problemas éticos e sociais emersos do extraordinário aumento dos conhecimentos e da capacidade de controle relativos aos processos viventes. Existem hipóteses variadas sobre a data exata de nascimento da bioética ${ }^{8}$, mas esta disputa é aqui irrelevante, pois um processo histórico-cultural vasto e imponente como tal não nasce em um dia ou em um ano precisos, mas de forças que atravessam um longo período. A escolha de uma data em detrimento a outra possui um inevitável aspecto de convencionalidade, e sua adequação depende da perspectiva teórica da qual descendem as razões que a justificam.

A perspectiva que posiciona esse nascimento em 1971 é sustentada pela fundação, nesta data, do Kennedy Institute, na Georgetown University em Washington (D.C), e pela publicação do livro de John Rawls (1971), A Theory of Justice, que na filosofia moral de língua inglesa marcou a guinada em direção à ética normativa,

\footnotetext{
${ }^{8}$ Há quem o data junto ao processo de Nuremberg de 1946/47, de onde teria emergido o problema de instauração de barreiras éticas em relação à ciência para frear atrocidades como aquelas praticadas pelos nazistas; há quem o delimita ao ano de 1962, com a formação da chamada "God Commission" para decidir quem poderia ingressar na diálise, recém colocada à disposição; outras pessoas ao ano de 1967, com a publicação de um célebre artigo de H. Beecher sobre experimentações impróprias; assim como, ao de 1971, com a formação do "Kennedy Institute for the study of human reproduction and bioethics".
} 
afastando-se da metaética, e estabelecendo, assim, as bases para a passagem às éticas aplicadas. De fato, a publicação de um livro, por si só, não produz uma transformação tão importante, e talvez seria melhor dizer que o ambiente cultural estava pronto e o sucesso de $A$ Theory of Justice não fez outra coisa senão acender a pólvora. Algo similar vale também em relação ao Kennedy Institute, que foi precedido por instituições análogas (como o Hastings Center em Nova York): sua importância está no fato de que, ao instituir-se em uma grande universidade, teve o papel de impulsionar outras universidades e instituições. Além disso, o Kennedy Institute logo promoveu a Encyclopedia of Bioethics, o que lançou a nova disciplina no plano cultural.

Estas recordações são ótimas razões para sustentar a escolha de 1971 como data do nascimento da bioética, mas há outra relativa à estrutura do recém-fundado Kennedy Institute. O instituto é expressão de uma universidade dirigida por jesuítas e tem como escopo específico o aprofundamento de temas éticos: não obstante a direção do instituto é atribuída a um laico, o ginecólogo E. André Hellergers. Um fato que, por si só, indica de forma direta a estrutura desteologizante da nascente bioética: há alguns anos, seria impensável que uma universidade dirigida por religiosos fundasse um instituto dedicado ao aprofundamento de temas éticos essenciais e controversos, e que atribuísse sua direção a um laico e não a um clérigo. Eis um sentido no qual a desteologização está na base da bioética já em sua fase inicial.

Mas há outro aspecto implícito em tal escolha: atribuindo a direção do Kennedy Institute a um médico laico é sancionada a interdisciplinaridade da reflexão bioética e tem-se, com essa, a superação da tradição hierárquica das ciências que via a teologia no vértice da pirâmide. Em outras palavras, a pesquisa bioética foi também desteologizada por meio de algo como uma democratização das ciências: anteriormente, a teologia se encontrava em posição de guiar a pesquisa intelectual, enquanto que agora se encontrará a disciplina que, com relação a um tema específico, se revelar capaz de chegar a contribuições significativas para a própria pesquisa. 


\section{A desteologização da bioética no plano cultural: a "trindade dos teólogos" e seu legado}

A desteologização estrutural da nascente bioética em seu plano institucional, por si só, não exclui que, no plano cultural, permaneçam fortes ligações com a teologia. Não só a bioética nasce em uma universidade dirigida por religiosos, mas ressalta-se que "três teólogos guiaram a criação da bioética: Joseph Fletcher, um bispo episcopal, Paul Ramsey, um professor metodista, e Richard McCormick, um teólogo moral jesuíta" (JONSEN, 1998, p.41). Todavia, como prossegue Jonsen, "essa trindade [de teólogos], de forma diferente à divina trindade da teologia cristão, não era 'uma e indivisa', mas, antes, formava um espectro de opiniões que variava do liberal Fletcher, ao conservador Ramsey, com McCormick se posicionando no centro moderado" (Ibidem, p. 41-2).

Três importantes tradições teológicas cristãs influenciaram o nascimento da reflexão bioética, fazendo emergir, nitidamente, o difuso pluralismo ético que caracteriza a disciplina. Entretanto, aqui também há um traço radicalmente novo que distingue o debate bioético daqueles precedentes. A pluralidade das confissões religiosas (cristãs e não) era conhecida há bastante tempo e sabia-se que a tarefa de uma tradição moral era aquele de moldar e dirigir as pessoas fiéis que nela nascem, crescem, vivem e morrem. Que havia religiões e tradições morais diversas, e que cada uma dessas determinasse a orientação existencial das pessoas fiéis era um fato evidente e nada surpreendente.

A novidade trazida pelo pluralismo ético que dá forma a bioética está no fato de que agora a pessoa interessada pode escolher a tradição moral que parece mais adequada à própria orientação ou modo de vida. Anteriormente, a pluralidade era um dado no qual cada pessoa se encontrava a viver, enquanto que, agora, a pluralidade é o dado que está na base de escolha da tradição na qual se quer viver. É verdade que na origem da bioética estão três tradições morais religiosas, mas o pluralismo ético que essas manifestam é suscetível de implicar uma mudança radical em relação ao modo de entender a religião e a sua função. Antes, 
o indivíduo nascia em uma religião e era determinado por essa; agora, é o indivíduo que escolhe a própria religião.

Dentre as muitas razões que podem ter influenciado o novo modo de compreender o pluralismo ético está a necessidade de dar uma resposta à dita exigência teórico-justificativa dos juízos morais, herdada da reflexão metaética. Por quase um século essa última havia habituado a procurar as razões que poderiam justificar os juízos morais e a sublinhar que nem o costume social, a autoridade (inclusive teológica) ou, ainda menos, as asserções metafísicas poderiam ser boas razões. A "navalha de Hume", com a distinção entre "fatos" e "valores", passou a demandar tanto a pesquisa sobre as "boas razões" quanto a elaboração de teorias éticas normativas de amplo alcance (como o utilitarismo) capazes de fornecer essas razões de modo sistemático e coerente. Em um sentido, a difusão da exigência teórico-justificativa também acarretou uma outra novidade em relação à tradição, já que tal exigência possui a pretensão de submeter à exame crítico a opinião recebida das tradições morais para, assim, verificar se são efetivamente sustentáveis ou não.

Enquanto, em precedência, era dado como fato que uma tradição moral se auto sustentasse e que a antiguidade de uma opinião derivada dessa tradição, por si só, comprovasse seu valor; agora, a situação se inverte e, se há a pretensão de reformar as opiniões recebidas e a moral de senso comum, isso se dá tendo por base teorias éticas de referência ${ }^{9}$. Anteriormente, a tradição moral era o critério de referência para julgar as várias posições internas a ela; contemporaneamente, a própria tradição é objeto de valoração, tendo como base para tal processo critérios fornecidos pelas teorias éticas. Fletcher, Ramsey e McCormick respondem a essa nova exigência teórico-justificativa, suas obras visam demonstrar a validade e a fecundidade da

\footnotetext{
9 Pode-se dizer que, em âmbito moral, foi retomado um programa análogo àquele proposto pelo neopositivismo, que incluía uma reforma e um afinamento da linguagem como meio dos resultados obtidos da nova lógica simbólica.
} 
própria tradição teológica moral, e não, ao contrário, dar por certa sua bondade.

Não apenas essa nova abordagem visando reformar a moral de senso comum envolveu legislações e a opinião pública, mas, no plano cultural, proporcionou um salto relativo à reflexão, que se torna mais "racional" e atenta às justificações. Isso acarretou a desteologização da reflexão moral, tendo em vista que já não bastava o chamado a uma autoridade divina para sustentar a validade de um juízo. Ao contrário, essa atitude é colocada "fora de jogo" desde o começo, já que as razões apresentáveis são "públicas" enquanto o referimento a uma religião passa ao "privado". Assim, apresenta-se outro sentido segundo o qual a bioética é radicalmente desteologizada.

\section{A desteologização da bioética no plano do objeto da reflexão}

A desteologização da bioética abrangeu também outro aspecto cuja explanação faz com que se recorde que a teologia tem como objeto a religião, termo com o qual se entende "uma crença em, e uma atitude deferente em relação a um ser sobrenatural em confronto ao qual o homem se sente dependente e ao qual se apela em atos de culto. [...] A crença em seres sobrenaturais é sem dúvida baseada em um sentimento de desconhecimento (uncanniness) ou de mistério" (WESTERMARCK, 1939, p.01) ${ }^{10}$. A teologia, então, se refere à realidade adscrita ao sobrenatural e, por isso, a ciência moderna foi (e continua a ser) um dos fatores propulsores da desteologização: a ciência fornece uma explicação naturalística dos fenômenos cuja ocorrência era atribuída, em

\footnotetext{
10 "I take religion in the abstract [...] to be belief in and a regardful attitude towards a supernatural being, on whom man feels himself dependent and to whom he makes an appeal in his worship. [...] The belief in supernatural beings is undoubtedly based on a feeling of uncanniness or mystery. Men distinguish between phenomena that they are familiar with and consequently ascribe to 'natural' causes, and other phenomena that seem to them unfamiliar and mysterious and are looked upon as 'supernatural', or are supposed to spring from 'supernatural' causes" (WESTERMARCK, 1939, p.01).
} 
precedência, a causas sobrenaturais. Nos últimos quatro séculos, esse processo envolveu, sobretudo, o mundo inorgânico, por meio dos avanços da astronomia e da físico-química. O mundo orgânico estava apenas contornado pela influência desses avanços, de modo que permaneceu, mais longamente, a ideia de que nele operariam causas sobrenaturais.

Para apreender esse aspecto é suficiente ler as palavras do cardeal Giuseppe Siri, pronunciadas no discurso de abertura da XXVI Semana dos Católicos da Itália, dedicada aos problemas populacionais e à crítica ao controle de natalidade proposto pelas doutrinas neomaltusianas. Era setembro de 1953, e, tendo como tema específico "o direito à vida", o cardeal iniciava observando que "a vida, eu não devo defini-la, devo convidar somente a observá-la; todos a conhecem e a identificam. [...] Posso falar da 'vida' como de um fato universal, que por toda parte pulsa, que por toda parte [...] abre e fecha ciclos" (SIRI, 1954, p.20. Grifo nosso). O cardeal passava, então, à questão central: "este 'fato' do universal, infalível e misterioso movimento da vida, é um sujeito de 'direito', portanto, faz com que eu possa falar em 'direito à vida'?" (Ibidem, p.20). A resposta é um enfático Não!, porque "o direito tem por sujeito a pessoa física e - por extensão - a pessoa moral. Não tem por sujeito um fato. Mas aqui o fato persiste e conclama. É claro então que devo usar a palavra 'direito' em um significado analógico e não em sentido estrito. Essa palavra, em realidade, é utilizada aqui para indicar que o fato da vida é vetor e revelador de uma vontade divina, aquela que os homens são obrigados a respeitar, 'que o percurso da vida' do mundo é mantido em tal lugar e em tais termos segundo a disposição do Criador. Que se deva esforçar-se pela vida; que nada seja mortificado indevidamente; que ninguém seja autorizado à diminuir, de nenhum modo, o direito do Senhor da vida" (Idem) ${ }^{11}$. Nesse sentido, continua Siri, "se se trata do fato

\footnotetext{
${ }^{11}$ A expressão "o percurso da vida", que Siri reporta entre aspas, parece ser tirada da longa Lettera della Segreteria di Stato di Sua Santità enviada pelo então Pro-Segretario, G.B. Montini, ao Congresso da Settimana Sociali dei Cattolici d'Italia, de 1953, na qual afirma que "É crime, então, [...] qualquer atentado
} 
'vida', o direito, no sentido analógico dito anteriormente, exigese que não se impeça que essa mesma vida siga o percurso a ela dada por Deus. Isto em todos os sentidos e em todos os campos, do respeito à fertilidade conjugal à defesa do otimismo sensato no mundo. Somente a negação de Deus e de uma Providência, mesmo contra todas as evidências da ordem e da teleologia na Criação, pode permitir a alguns homens considerar planos e projetos com objetivo de corrigir as vias atribuídas por um arquiteto desconhecido, também entendidas como insensatas. De fato, atrás do fato vida está Deus, e a ele é que se deve respeitar, respeitando a vida" (Idem).

Não é esse o momento de considerar a distinção entre o direito à vida em sentido estrito (reservado apenas à pessoa: física e moral) e o direito à vida em sentido analógico (atribuível a todo o percurso da vida, dos genitores ao berço). O ponto que nos interessa é a atitude de fundo revelada das palavras reportadas acima que deixam transparecer uma natural e imediata reverência relativa ao processo vital humano visto como diretamente dependente de Deus. Ao cardial e a seus ouvintes parece normal e óbvio afirmar que "o fato da vida é vetor e revelador de uma vontade divina" ou que "o percurso da vida do mundo é mantido em tal lugar e em tais termos segundo a disposição do Criador". Para eles é fácil observar que a pretensão de negar Deus se coloca "contra todas as evidências da ordem e da teleologia na Criação" e depende somente da vã tentativa de impedir que a "vida siga o percurso a ela dada por Deus" ou de diminuir "o direito do Senhor da vida".

Desperta surpresa aos nossos olhos ver como para Siri e seus ouvintes era de todo óbvio a ideia que o "percurso da vida, dos genitores ao berço" compreendesse uma direta intervenção da divindade. Hoje, essas palavras soam, no mínimo, estranhas senão incompreensíveis. Sinal de que a atitude difundida ou "modo de

à vida em seu percurso dos genitores ao berço, e com isso não está incluso apenas a morte direta do inocente, mas também a fraude contra as intenções da natureza que, enquanto tais, exprimem a vontade do Criador" (MONTINI, 1954, p. 13). 
ver" adotado se transformou completamente: o sobrenatural foi expulso do processo reprodutivo, e Deus não mais o habita ou é bem-vindo. O "desencantamento do mundo" foi estendido para essa porção da realidade. A desteologização da bioética referese, assim, ao objeto mesmo da reflexão, que é hoje observado com novos olhos e de um ponto de vista novo. Pode-se dizer que a Revolução científica, primeiramente, e, posteriormente, a industrial trouxeram a desteologização das relações econômicas, jurídicas e políticas; por sua vez, a Revolução biomédica (MORI, 2013) em curso está desteologizando as relações acerca da vida (humana e não humana $)^{12}$.

\section{O efeito abrangente da desteologização da bioética: a afirmação de uma nova "forma de vida" ou de uma "orientação fundamental" da civilização}

Ao apreender em conjunto os aspectos aqui relevados pode-se dizer que a desteologização da reflexão acarretou uma transformação da vida, do pensamento e das atitudes difusas tão fundamental que torna possível comparar a Bioética ao Romantismo, do qual se disse que representou "a maior mutação singular ocorrida na consciência do Ocidente" (BERLIN, 2001, p.24). A bioética também modificou, de maneira substancial e permanente, o "modelo dominante" que dá forma ao nosso modo de viver: "a história, não somente do pensamento, mas também da consciência, das opiniões, das ações, da política e da estética é, em grande medida, uma história de modelos dominantes. Cada vez que olhamos para uma determinada civilização, qualquer que

\footnotetext{
${ }^{12}$ Com "Revolução biomédica" entendo o processo histórico caracterizado pelo extraordinário aumento do conhecimento biomédico e da capacidade de controle da vida (humana ou não humana). Como a Revolução Industrial difundiu a primeira secularização (ou secularização primária) em relação ao mundo astronômico e inorgânico, assim a Revolução biomédica está difundindo uma segunda secularização (secularização secundária) em relação ao mundo orgânico. Para um desenvolvimento dessa noção ver MORI, 2013.
} 
seja, encontramos que o mais característico de seus escritos e de seus outros produtos culturais reflete uma particular forma de vida, que domina aqueles que escreveram tais textos, ou pintaram tais quadros, ou composto tais obras musicais. E para identificar uma civilização, para explicar de qual tipo de civilização se trata, para entender o mundo no qual essas pessoas pensaram, sentiram e agiram, é importante buscar, no limite do possível, isolar a forma dominante que aquela cultura obedece" (Idem). Pode-se acrescentar que um "modelo dominante" é aquele que caracteriza os modos de categorizar a realidade, de posicionar-se em relação a essa e de prospectar o futuro, imprimindo, assim, direção ao modo de viver, mesmo que não se tematize ou conceitue os vários elementos implicados.

Embora não seja fácil individuar seu núcleo, ainda podese dizer que o Romantismo "criou uma grande revolução da consciência” (BERLIN, 2001, p.48). Algo análogo vale também para a Bioética: mesmo que seja difícil individuar seu núcleo, ela explicitamente transformou o "modelo dominante" da civilização e imprimiu uma nova orientação fundamental em correspondência à nova "forma de vida". Quase como por mágica, em poucas décadas, deus saiu (ou foi expulso) do âmbito da vida física (humana e não humana) e, hoje, pouquíssimas pessoas pensariam dizer publicamente que é Deus que marca o percurso da vida e que "atrás do fato vida está Deus, e a ele é que se deve respeitar, respeitando a vida" (SIRI, 1924, p.20) . Ao contrário, a desteologização da bioética posiciona ao centro do discurso o consentimento informado, ou seja, a base teórica que justifica a soberania sobre o corpo e sobre a transmissão da vida. Do qual descende a ideia de que aborto e eutanásia sejam "direitos fundamentais": enunciado que mostra quão revolucionária é tal nova forma de vida.

Em um sentido, a afirmação do consentimento informado no âmbito bioético tem um papel análogo àquele que a afirmação da soberania popular teve em âmbito político. Essa última suscitou, nos séculos passados, grandes controvérsias, e para apreendê-las basta ler as duras palavras com as quais Stefano De BOULOGNE (1825), bispo de Troyes, condenava a ideia "que os Reis tenham 
do povo a sua autoridade" (p.13). Esta é "a imunda quimera da turva demagogia, [...] a mentira mais cruel [...] para seduzir a multidão" e que leva a uma "doutrina anárquica e antissocial" oposta ao direito natural e "destrutiva em relação à autoridade do Rei não menos do que a de Deus" (Ibidem, p.14). Concluindo, afirma: "Não, não é verdade que o povo seja soberano, nem que os Reis sejam seus mandatários; não mais que os pais sejam os mandatários de seus filhos, ou os tutores de seus pupilos" (Ibidem, p.13). Hoje, também assistimos um debate semelhante acerca do consentimento informado: aspecto que confirma a profundidade da transformação e a plausabilidade da analogia proposta.

Para completar o quadro pode-se observar que o processo da desteologização da forma de vida não abrange apenas as margens da vida física, onde estão os temas de início e fim de vida, privilegiados pela bioética (aborto e eutanásia). O processo envolve, cada vez mais, a parte central da vida, ou seja, aquela que se refere à alimentação e os chamados "estilos de vida". Para compreender a profundida da transformação em foco, basta lembrar que as religiões mantinham uma regulação da alimentação e da dieta ${ }^{13}$. Graças a essas regras dietéticas, as religiões podiam reafirmar com frequência a soberania de deus sobre a vida, enquanto que agora, esse âmbito torna-se amplamente regulado pela dietética científica. A cozinha, que já foi uma espécie de sacristia na qual se preparava a celebração do alimento, agora é governada pelo(a) cozinheiro(a) ou chef: um técnico que busca equilibrar as exigências dietéticas com os prazeres do paladar. Dietas científicas e exercícios físicos em acadêmias são as atividades de uma nova "forma de vida" centrada no corpo: atividades que tomam o lugar dos ritos tradicionais de oração e celebração dos alimentos. O sucesso atingido por cursos de culinária, dietas, acadêmias e centros de bem-estar, confirma a afirmação de um novo "modelo cultural" que prevê critérios similares àqueles que acarretaram a desteologização da bioética.

\footnotetext{
${ }^{13}$ Devo esta observação a uma conversa com Maria Teresa Busca, coordenadora da seção de Turim da Consulta di Bioetica Onlus.
} 


\section{Conclusão}

\section{Um efeito da desteologização da bioética: o nascimento de uma nova ética independente da religião.}

Sustentei que, longe de ser uma disciplina particular respectiva a um setor específico, a bioética é um movimento cultural revolucionário que, como o Romantismo, modificou a orientação fundamental da civilização e afirmou uma nova forma de vida. O aspecto central dessa transformação está na desteologização da reflexão bioética: a vida humana, que até poucos anos era vista como misteriosa e sujeita à intervenção divina, ingressa no âmbito naturalístico com a consequente perda do sentido de dependência em relação ao transcendente.

Muitos falam de "colapso da moralidade" ou de "morte da ética", como já feito no passado com o advento de novas instituições, como o direito ou a política. Contra essa prospectiva apocalíptica, pode-se observar que a desteologização da bioética possibilita a superação da ética tradicional, pautada em proibições absolutas, criando assim espaço para uma nova ética com novas prioridades. O outono de uma civilização não abre as portas para o abismo do nada (como defendido pelos conservadores), mas abre a estrada para a primavera de uma civilização nova e renovada, que se espera melhor que a precedente. Já assistimos, na civilização ocidental, a emergência de novas instituições, nascidas a partir da desteologização de setores específicos. Após o nascimento da ciência moderna no século XVII, deu-se, no século seguinte, a afirmação da economia. No século XIX, foi a vez do direito e no século $X X$, a da política. A ética tem sua vez no fim do século $X X$ e início do XXI. O nascimento de cada uma dessas instituições complexificou a vida social por meio de processos grandiosos. $\mathrm{O}$ nascimento da ética é, talvez, ainda mais grandioso, pois envolve os ideais e os interstícios da existência, como também as convenções profundas que se mantiveram inalteradas por milênios. Nascem centros de ética e comitês de bioética, fatos que testemunham que, no plano prático e organizativo, a ética está se institucionalizando. 
Algumas pessoas observam que a bioética possui uma especificidade que a distingue dos casos precedentes, porque aqueles abrangiam a vida social enquanto que, agora, se atinge o nível da vida biológica. A diversidade do tema deveria trazer uma reflexão sobre a importância do novo passo dado. Todavia, preocupações análogas emergiram no passado e, seguramente, a desteologização da bioética é portadora de uma profunda transformação de valores, como já sublinhamos. Mas isso pode trazer um enriquecimento da civilização e uma forma de vida melhor em relação à precedente. Como parece exemplificar o caso dos movimentos por maior igualdade, que buscam superar antigas discriminações de raça, sexo e de gênero. Busca-se, também, a igualdade a todos os sencientes, por meio da superação do tradicional modelo antropocêntrico.

Estamos a percorrer um longo caminho, assim não é possível dizer como será o futuro. Pode-se notar que a desteologização se impôs fortemente nas primeiras décadas da bioética até aquela de 1990. Nessa primeira fase, a reflexão formou-se a partir do impulso reformador dos movimentos pelos direitos civis e da utopia acerca da possibilidade de uma rápida transformação da sociedade. A bioética parecia animada pela esperança de poder modificar a opinião pública e chegar rapidamente a novas leis e formas de organização social. A partir dos anos 90 do século passado, a situação muda rapidamente e se verifica uma desaceleração do processo com um retorno a alguns registros tradicionais. Mesmo na bioética foi possível sentir a influência da chamada "revanche de Deus" e o consequente gosto pelas ditas origens e tradições. Na Itália, esse processo foi explícito, considerando-se que nos anos de 1970 foram aprovadas leis progressistas (divórcio, novos direitos familiares, aborto), enquanto que nos anos 1990 foi reforçado o movimento conservador, que na década seguinte é bem sucedido ao aprovar a lei $40 / 2004^{14}$ e a fazer falir o referendo revogativo de 2005.

${ }^{14} \mathrm{NT}$ : Lei italiana que restringe o acesso aos métodos de reprodução assistida. 
$|302|$

A desteologização da bioética...

Por vezes, lamenta-se disso dizendo que a Itália sofre a influência negativa do Vaticano. Há verdade em tal lamentação, pois nesse país o tom da situação é mais agudo do que alhures. Entretanto, o fenômeno é generalizado, exemplificado pela dificuldade de mudanças legislativas relativas à bioética: mudanças aconteceram em pequenos países, como a Holanda e a Bélgica, mas as democracias das grandes nações custam a produzir as reformas preconizadas pelo "modelo dominante" estabelecido com a bioética. Isso parece ocorrer devido ao que é exposto em um verso de Yeats ${ }^{15}$ (ligeiramente modificado): "aos inovadores faltam fortes convicções, enquanto que os conservadores são plenos de intensa paixão". Os conservadores apresentam-se em bloco e conseguem impedir ou atrasar as transformações. Registra-se, como forma de desbloquear essas situações, uma maior intervenção das Cortes supremas, que, apelando diretamente às constituições, dão respostas a temas bioéticos. Assim, nos Estados Unidos, em 2013, a Corte suprema interveio para sancionar o casamento gay; na Itália, em 2014, o Tribunal constitucional desmantelou parte da lei 40; no Canadá, em 6 de fevereiro de 2015, foi declarada inconstitucional a lei que proibia a eutanásia e foi estabelecido o prazo de um ano para apresentação de uma nova lei. É difícil fazer previsões acerca dos desenvolvimentos futuros, mas, por agora, apontamos as dificuldades encontradas pelos movimentos reformadores: a desteologização da bioética encontra amplas forças contrárias. E, talvez, esse seja um outro sinal de quão profunda seja a guinada impressa por esse processo.

\section{Referências}

BERLIN, I. Le radici del romanticismo. Milano: Adelphi, 2001.

De BOULOGNE, SA. Istruzion pastorale di Monsignor De Boulogne vescovo di Troyes sull'amore e sulla fedeltà che

\footnotetext{
${ }^{15} \mathrm{O}$ verso está em The Second Coming: "The best lack all conviction, while the worst/Are full of passionate intensity" (YEATS, 1996, p.107).
} 
francesi devone al Re, e sul ristabilimento del cattolicismo in Francia. Memorie di Religione, Morale e Letteratura. Moderna: Eredi Soliano. Tomo VIII, 1825.

JONSEN, A. The Birth of Bioethics. Oxford: Oxford University Press, 1998.

LEINKAULF, T. Giordano Bruno Werke. Intervista a Thomas Leinkaulf. Lo sguardo, Rivista di Filosofia. n.2, v.6, 2011.

MONTINI, GB. Lettera della Segreteria di Stato di Sua Santità. Settimana Sociali dei Cattolici d'Italia. I problemi della popolazione. XXVI setimana sociale, Palermo, 27 settembre -3 ottobre 1953. Roma: ICAS, 1954.

MORI, M. Manuale di Bioetica. Verso una civiltà biomedica secolarizzata. Firenze: Le Lettere, 2013.

RAWLS, J. A theory of justice. Cambridge: Harvard University Press, 1971.

SIRI, G. Prolusione. Settimana Sociali dei Cattolici d'Italia. I problemi della popolazione. XXVI setimana sociale, Palermo, 27 settembre - 3 ottobre 1953. Roma: ICAS, 1954.

URRESTI, TJ. Diritto canonico e teologia due scienze diverse. Concilium, III, n. 8, 1967. Disponível em: <http://canonistica.org/ urresti1.htm>. Acesso em: 8 jan. 2018.

WESTERMARCK, E. Christianity and Morals. London: Kegan Paul, Trench, Trubner \& Co, 1939.

YEATS, WB. The second coming. In: . The Collected Poems of W.B. Yeats. New York: Simon \& Schuster. p. 107-8. 
